\title{
Size effect in reactivity of copper nanoparticles to carbon tetrachloride degradation
}

\author{
Ya Hsuan Liou, Shang Lien Lo*, Chin Jung Lin
}

Research Center for Environmental Pollution Prevention and Control Technology, Graduate Institute of Environmental Engineering, National Taiwan University, Taipei 106, Taiwan

\section{A R T I C L E I N F O}

Article history:

Received 11 August 2006

Received in revised form

13 December 2006

Accepted 8 January 2007

Available online 6 March 2007

Keywords:

Carbon tetrachloride

Nanoparticle

Size effect

Zero valent metal

\begin{abstract}
A B S T R A C T
Surface area-normalized rate constants $\left(k_{\mathrm{SA}}\right)$ of reaction between metallic nanoparticles and reducible contaminants, such as chlorinated hydrocarbons, heavy metals, and nitrate, have been reported to be dramatically increased as compared to that of commercial metallic powder. However, $k_{\mathrm{SA}}$ for individual pollutants in previously published data vary by as much as 1-2 orders of magnitude and much of this variability is due to the effect of various sizes. The size dependence of the reactivity of nanoparticles is not yet fully understood; however, yielding nanoparticles with uniform size and without agglomeration during the period of reaction would demonstrate the effect of varying particle size. In this study, resin-supported zerovalent copper with average particle size of 7, 10, 18, 26, and 29, respectively, were successfully synthesized and evidenced no agglomeration during the reaction period of $10 \mathrm{~h}$. The $k_{\mathrm{SA}}$ of copper nanoparticles $\left(k_{\mathrm{n}, \mathrm{SA}}\right)$ was $110-120$ times higher than that of powdered copper particles $\left(k_{\mathrm{p}, \mathrm{SA}}\right)$ when the copper particle size was about $10 \mathrm{~nm}$. However, for diameters of $18-29 \mathrm{~nm}$, the ratio of $k_{\mathrm{n}, \mathrm{SA}} / k_{\mathrm{p}, \mathrm{SA}}$ was around $10-20$, indicating that the reactivity of small copper nanoparticles $(\sim 10 \mathrm{~nm})$ varies discontinuously. Thus, most variability in previous $k_{\mathrm{SA}}$ is attributed to the presence of small nanoparticles.
\end{abstract}

c 2007 Elsevier Ltd. All rights reserved.

\section{Introduction}

Extensive researches over the past 15 years have demonstrated that chemical reduction of many substances in the environment can be coupled with oxidation of zerovalent metals ( $\left.\mathrm{M}^{0}\right)$ (Gillham and O'Hannesin, 1994; Matheson and Tratnyek, 1994; Orth and Gillham, 1996; Agrawal and Tratnyek, 1996). In the reductive dechlorination reaction by $\mathrm{M}^{0}$, for example, the anodic $\mathrm{M}^{0}$ is oxidized into $\mathrm{M}^{n+}$ ions ( $n$ is valence), and chlorinated hydrocarbons, denoted as $\mathrm{RCl}$, as electron acceptors are converted to hydrocarbons and chlorides under anaerobic conditions. The chemistry of the $\mathrm{M}^{\mathrm{O}} / \mathrm{RCl} / \mathrm{H}_{2} \mathrm{O}$ system is similar to that of the corrosion of $\mathrm{M}^{0}$ by $\mathrm{RCl}$ substituting oxygen as the oxidant. In this process, $\mathrm{RCl}$ are mostly transformed into benign compounds such as hydrocarbons $(\mathrm{RH})$ and chlorides $\left(\mathrm{Cl}^{-}\right)$.

A surface-area-normalized kinetic model is most commonly used for heterogeneous reactions between reducible contaminants and metallic particles. This model assumes that the degradation rate of a contaminant is first order with respect to both total metallic surface and contaminant concentration, expressed as follows:

$-\mathrm{d}\left[\mathrm{C}_{\mathrm{w}}\right] / \mathrm{dt}=k_{\mathrm{SA}} a_{\mathrm{s}} \rho_{\mathrm{m}}\left[C_{\mathrm{w}}\right]=k_{\mathrm{SA}} \rho_{\mathrm{a}}\left[C_{\mathrm{w}}\right]=k_{\mathrm{obs}}\left[C_{\mathrm{w}}\right]$,

where $k_{\mathrm{SA}}\left(\mathrm{Lh}^{-1} \mathrm{~m}^{-2}\right)$ is a surface area-normalized rate constant, $a_{\mathrm{s}}\left(\mathrm{m}^{2} \mathrm{~g}^{-1}\right)$ is the specific surface area of metal, $\rho_{\mathrm{m}}$ $\left(\mathrm{gL}^{-1}\right)$ is the metal mass loading in the reactor, $\rho_{\mathrm{a}}\left(\mathrm{m}^{2} \mathrm{~L}^{-1}\right.$ of solution) is the surface area concentration of metal, $k_{\text {obs }}$ is the

*Corresponding author. Tel.: +8862 23625373; fax: +886223928821.

E-mail address: sllo@ntu.edu.tw (S.L. Lo).

0043-1354/\$ - see front matter ( 2007 Elsevier Ltd. All rights reserved.

doi:10.1016/j.watres.2007.01.014 
observed rate constant, and $C_{w}$ is the concentration of a contaminant. The amount of available surface area is the most important factor that governs the reduction rate. Studies have demonstrated the linear relationship between $k_{\text {obs }}$ and $\rho_{\mathrm{m}}$ for carbon tetrachloride (Matheson and Tratnyek, 1994), 1,2-dibromo-3-chloropropane (Siantar et al., 1996), nitrobenzene (Agrawal and Tratnyek, 1996) and trichloroethene (Su and Puls, 1999). Additionally, reducing the diameter of the iron particles to vary the $a_{\mathrm{s}}$ values also proportionally accelerates the apparent rate of dechlorination reaction (Siantar et al., 1996).

Dimensions of metallic particles in the range $1-100 \mathrm{~nm}$ possess the advantages of larger specific surface area and higher surface reactivity over microscale powder to increase the chemical reduction rate of reducible contaminants. For example, the reduction rates for chlorinated methanes (Lien and Zhang, 1999; Feng and Lim, 2005), chlorinated ethenes (Wang and Zhang, 1997; Li et al., 2003), chlorinated benzenes (Lowry and Johnson, 2004), arsenic (Kanel et al., 2005), and nitrate (Liou et al., 2006) by iron nanoparticles on a mass basis were more than 2 orders of magnitude higher than those of commercial iron powder. Nanoparticles can be anchored onto a solid matrix for treatment of water, wastewater, and gaseous steams (Meyer et al., 2004). Additionally, direct subsurface injection of iron nanoparticles to effectively degrade chlorinated organic compounds has been demonstrated (Cantrell et al., 1997). The technology provides enormous flexibility for in situ or ex situ remediation. Values of $k_{\mathrm{SA}}$ are most often used to compare reactivity of nanoparticles to that of microscale powder, and are also critical parameters for the design of full-scale remediation operations. With the abundance of kinetic data now available for many compounds, $k_{\mathrm{SA}}$ varying by 1-2 orders of magnitude for individual compounds can be observed. The $k_{\mathrm{SA}}$ value for trichloroethene $\left(\mathrm{C}_{2} \mathrm{HCl}_{3}\right)$ reduced by iron nanoparticles as reported by Wang and Zhang (1997) is $3 \times 10^{-3} \mathrm{Lh}^{-1} \mathrm{~m}^{-2}$, nearly similar to the results of Liu et al. (2005) $\left(k_{\mathrm{SA}}=2 \times 10^{-3} \mathrm{~L} \mathrm{~h}^{-1} \mathrm{~m}^{-2}\right)$, though not as high as that reported by $\mathrm{He}$ and Zhao $\left(k_{\mathrm{SA}}=2 \times 10^{-2} \mathrm{Lh}^{-1} \mathrm{~m}^{-2}\right)$. Moreover, the differences in $k_{\mathrm{SA}}$ between the results of Lien and Zhang (1999) and Feng and Lim (2005) for carbon tetrachloride $\left(\mathrm{CCl}_{4}\right)$ and chloroform $\left(\mathrm{CHCl}_{3}\right)$ vary by 1 and 2 orders of magnitude, respectively. In this case, the utility of $k_{\mathrm{SA}}$ values in the design of a treatment system would be questionable.

Iron nanoparticles were typically prepared by borohydride reduction of an aqueous iron salt (Wang and Zhang, 1997; Choe et al., 2001; Ponder et al., 2000; Schrick et al., 2002; Liao et al., 2003). However, due to the extremely high reactivity, the initially formed nanoaprticles tended to be either oxidized quickly by surrounding media or to agglomerate during the reaction period, resulting in a rapid change in the number of reactive surface sites. Unfortunately, $a_{\mathrm{s}}$ determined by $\mathrm{N}_{2}$ isothermal adsorption (the BET surface area) presents the total surface area including both exposed surface of redoxactive metal and redox-inactive metal oxide. This may not provide a true representation of the actual number of sites on the iron surface.

A more extreme source of variability in $k_{\mathrm{SA}}$ results from the effect of various sizes. Iron nanoparticles prepared by a solution method with $\mathrm{NaBH}_{4}$ as a reductant have sizes between 1 and $100 \mathrm{~nm}$ with an average diameter of $57 \pm 16 \mathrm{~nm}$ (Cao et al., 2005). Applying a stabilizer to modify the solution method has been developed for the formation of much smaller nanoparticles. Li et al. (2003) used cetyltrimethylammonium bromide as a stabilizer in the water-in-oil microemulsion system to obtain the average particle size of about $10 \mathrm{~nm}$. The results of their research indicated that the initial dechlorination rate for microemulsion nanoparticles was 2.6 times higher than that for the solution nanoparticles. He and Zhao (2005) applied a water-soluble starch as a stabilizer to prepare starched-iron nanoparticles. The mean particle size was $14 \pm 12 \mathrm{~nm}$ with much of the particles less than $10 \mathrm{~nm}$. The starched nanoparticles exhibited values of $k_{\mathrm{SA}} 10$ times higher than those of the solution nanoparticles when used for dechlorination of $\mathrm{C}_{2} \mathrm{HCl}_{3}$. Additionally, our previous study (Liou et al., 2006), differing iron precursor concentrations to obtain various nanoparticle size distribution, indicated that the reactivity of iron nanoparticles with diameters of $9-10 \mathrm{~nm}$ for the denitrification of aqueous nitrate was higher than that of iron nanoparticles with diameters of $20-60 \mathrm{~nm}$ and of $20-70 \mathrm{~nm}$. The most likely cause for the high chemical reactivity of small iron nanoparticles is the rise in adsorbed atomic hydrogen $\left(\mathrm{H}_{\mathrm{ads}}\right)$ production on its surface. The peculiarity of these nanoparticles is due to their intrinsic heterogeneities: presence of different facets and presence of low coordinated edge sites (Henry, 2000). Thus, particle size is an important factor in controlling its reactivity.

In this study, the use of a support medium to stabilize and isolate a metal particle to clarify relations between size of copper nanoparticles and the reactivity to $\mathrm{CCl}_{4}$ dechlorination avoids the effect of agglomeration. The use of copper as a reductant was preferred due to the following: (1) The reliable in situ measurement of the surface area of resin-supported copper particles by temperature-programmed reduction (TPR) has been demonstrated (Grift et al., 1991), and (2) nanoscale zero valent copper exhibits relative stability in water, avoiding reaction with surrounding media. Nanoparticles with uniform size, and absence of agglomeration during the period of reaction would demonstrate the effect of varying particle size on its reactivity to the dechlorination of $\mathrm{CCl}_{4}$.

\section{Experimental section}

\subsection{Chemicals}

All aqueous solutions were made in water purified with a Milli-Q system $\left(18.2 \mathrm{M} \Omega \mathrm{cm}^{-1}\right)$. High-pressure liquid chromatography grade carbon tetrachloride was obtained from Aldrich (USA). Copper (П) nitrate trihydrate was from Alfa (USA). Copper powder was obtained from Riedel-de Haen (approx. $0.04 \mathrm{~mm},>99.5 \%$, GR grade, USA).

\subsection{Preparation of copper nanoparticles coated resin}

Firstly, the resin was exchanged with desired concentration of $\mathrm{Cu}^{2+}$ from an aqueous solution of $\mathrm{Cu}\left(\mathrm{NO}_{3}\right)_{2} \cdot 3 \mathrm{H}_{2} \mathrm{O}$, followed by thorough washing to remove excess physisorbed copper ions. After washing, the fresh samples were dried in air at $120^{\circ} \mathrm{C}$ for 
$12 \mathrm{~h}$. The dried samples were reduced from ambient to $300^{\circ} \mathrm{C}$ at $10^{\circ} \mathrm{C} \mathrm{min}^{-1}$ in a flow of $\mathrm{H}_{2} / \mathrm{N}_{2}\left(20 \mathrm{vol} \%, 100 \mathrm{~mL} \mathrm{~min}^{-1}\right)$ and keeping it at $300^{\circ} \mathrm{C}$ for $3 \mathrm{~h}$, then cooled down to room temperature in the reducing gas atmosphere. According the above description, five samples were prepared at various copper loading including 5, 10, 20, 30, 50 mg-Cu g-resin ${ }^{-1}$.

\subsection{Characterization of copper nanoparticles coated resin}

The oxidation states of copper on the resin were identified by electron spectroscopy for chemical analysis (ESCA). The ESCA measurements were perform by using a Vacuum Generators ECSALAB MKП photoelectron spectrometer (East Grinsted, $\mathrm{UK})$ with an $\mathrm{Al} \mathrm{K}_{\alpha} \mathrm{X}$-ray source $(1486.6 \mathrm{eV})$ and a hemispherical $150 \mathrm{~mm}$ mean radius electron analyzer with a take-off angle of $90^{\circ}$. During the data acquisition, the pressure in the sample chamber did not exceed $9.0 \times 10^{-9} \mathrm{~Pa}$. Hitachi H-7100 transmission electron microscopy (TEM) was used to characterize the size distribution of the metal particles.

\subsection{Surface area and average particle size of attached copper particles}

Two experiments were performed by TPR studies with the apparatus similar to that described previously (Bond and Namijo, 1989). TPR apparatus of standard design was allowed flows of (1) pure helium gas, (2) $10 \mathrm{vol} \% \mathrm{H}_{2}$ in $\mathrm{Ar}$, (3) pure $\mathrm{N}_{2} \mathrm{O}$ to be passed sequentially through the reactor and the thermal conductivity detector (TCD). Before these experiments, the fresh sample of $\mathrm{Cu}^{2+}$ on the resin was dried in air at $120^{\circ} \mathrm{C}$ for $18 \mathrm{~h}$. Then, it was heated in a flow of helium $\left(50 \mathrm{~mL} \mathrm{~min}^{-1}\right)$ from room temperature to $250^{\circ} \mathrm{C}$ at $10^{\circ} \mathrm{C} \mathrm{min}^{-1}$. Dwelling for $30 \mathrm{~min}$ at $250^{\circ} \mathrm{C}$ to remove the volatiles and then cooled down to room temperature. In the first TPR, a flow of $\mathrm{H}_{2} / \mathrm{Ar}(10 \mathrm{vol} \%$, Hoehloos) was used as reducing gas. The oven temperature was programmed from ambient to $350^{\circ} \mathrm{C}$ at $10^{\circ} \mathrm{C} \mathrm{min}^{-1}$ and held for $60 \mathrm{~min}$. Subsequently, the second TPR was to estimate the specific surface area and the particle size of $\mathrm{Cu}^{0}$ on the resin. In that, pure $\mathrm{N}_{2} \mathrm{O}$ (99.998 vol\%, Matheson) was used as oxidizing gas, helium gas (99.99vol\%, Hoekloos) as flushing gas and $\mathrm{H}_{2} / \mathrm{Ar}$ (10 vol\%, Hoehloos) as reducing gas. After the first TPR experiment, these gases were passed sequentially through the oven and detector. A sample of $\mathrm{Cu}^{2+}$ on the resin was reduced by the first TPR experiment, and then cooled down to room temperature. The flow of $\mathrm{H}_{2} / \mathrm{Ar}$ was then replaced by helium gas $\left(60 \mathrm{~mL} \mathrm{~min}^{-1}\right)$ to purge the reduced sample for $10 \mathrm{~min}$. Exposing the reduced sample to a flow of pure $\mathrm{N}_{2} \mathrm{O}\left(60 \mathrm{~mL} \mathrm{~min}^{-1}\right)$ at $100{ }^{\circ} \mathrm{C}$ for $120 \mathrm{~s}$, and then cooled down to room temperature in a flow of helium gas $\left(60 \mathrm{~mL} \mathrm{~min}^{-1}\right)$. Finally, a flow of $\mathrm{H}_{2} / \mathrm{Ar}\left(10 \mathrm{vol} \%, 60 \mathrm{~mL} \mathrm{~min}^{-1}\right)$ was introduced to reduce $\mathrm{CuO}_{2}$ on the $\mathrm{Cu}^{0}$ surface, named the second TPR.

\subsection{Reactor system}

The degradation and sorption of $\mathrm{CCl}_{4}$ by $\mathrm{Cu} /$ resin were measured in the closed batch system with zero headspace. In these systems, $0.2 \mathrm{~g} \mathrm{Cu} /$ resin and $14.8( \pm 0.05) \mathrm{mL}$ Ar-purged unbuffered Milli-Q water were added into $15 \mathrm{~mL}$ amber serum vials (Supelco). A $100 \mu \mathrm{L}$ aliquot of $\mathrm{CCl}_{4}\left(700 \mathrm{mgL}^{-1}\right)$ was then added under the water level. Immediately after $\mathrm{CCl}_{4}$ addition, the vials were capped with Teflon silicone septa and aluminum seals and then mixed on a rotary shaker $(50 \mathrm{rpm})$ at room temperature $\left(23 \pm 1^{\circ} \mathrm{C}\right)$ in the dark.

\subsection{Sample analysis}

Each vial was analyzed by liquid-liquid and liquid-solid extraction using $n$-hexane as a solvent to determine aqueous phase and total $\mathrm{CCl}_{4}$ concentration according the sampling method described in our previous study (Lin et al., 2005). The $\mathrm{CCl}_{4}$ concentrations were measured using a HP5890 GC equipped with a DB-624 capillary column and an electron capture detector operated in the splitless mode. The total $\mathrm{CCl}_{4}$ mass ( $\mathrm{mg}$ vial $^{-1}$ ) come from the sum of both the measured masses in the liquid-liquid and the liquid-solid extractions. Control total (mass per vial) concentrations were stable over the reaction period. The extraction recoveries for $\mathrm{CCl}_{4}$ from aqueous and sorbed phases in the blank resin vials $\left(0.2\right.$ g-resin vial $\left.^{-1}\right)$ were ranged from $91 \%$ to $103 \%$, that reasonable assumed this method can extract total $\mathrm{CCl}_{4}$ mass in vial. All experiments were duplicated or triplicated.

\section{Results and discussion}

\subsection{Characterization of copper nanoparticles coated resin}

The oxidation states of the resulting copper on the resin $\left(5 \mathrm{mg}-\mathrm{Cu}\right.$ g-resin $\left.{ }^{-1}\right)$ were characterized by ESCA. The XPS spectra of both the fresh prepared sample and the used one are presented in Fig. 1(a) and (b), respectively. These spectra consist of the Cu2 $\mathrm{p}_{3 / 2}$ main photoelectron peak (centered at 932.8-935.1eV). The Cu2 $\mathrm{p}_{3 / 2}$ peaks at binding energy of $932.8 \mathrm{eV}$ found in the XPS spectra of fresh prepared $\mathrm{Cu} / \mathrm{resin}$ (Fig. 1(a)) indicated nearly all copper in $\mathrm{Cu} / \mathrm{resin}$ is present as $\mathrm{Cu}^{0}$. This preparation process of $\mathrm{Cu} /$ resin was proven to be high enough to ensure nearly complete reduction to $\mathrm{Cu}^{0}$. After the dechlorination reaction of $\mathrm{CCl}_{4}$ for $10 \mathrm{~h}$, three $\mathrm{Cu} 2 \mathrm{p}_{3}$ / 2 peaks were found in the XPS spectra at binding energy of 932.8, 933.7 and $935.1 \mathrm{eV}$, corresponding to $\mathrm{Cu}^{0}, \mathrm{CuO}$ and $\mathrm{CuCl}_{2}$ with $4,10,86 \%$ of total copper loading by mole (the deconvolution results are shown in Fig. 1(b)). Thus, the XPS spectra of $\mathrm{Cu} /$ resin indicates the relative abundance of $\mathrm{Cu}$ (II) species on its surface after dechlorination reaction.

The morphology and size of the resulting $\mathrm{Cu}^{0}$ on the resin (10 mg-Cu g-resin ${ }^{-1}$ ) was viewed with TEM. Fig. 2(a) showed the copper particles were nearly spherical in shape and uniform in size with the average particle size about $10 \mathrm{~nm}$. After the dechlorination reaction of $\mathrm{CCl}_{4}$, copper particles didn't significant aggregate and presented similar particle size distribution (Fig. 2(b)).

According to the set of experiments of $\mathrm{Cu}^{0}$ surface oxidation in $\mathrm{N}_{2} \mathrm{O}$ flow at various temperatures by Evans et al. (1983), the surface area of $\mathrm{Cu}^{0}$ particles determined by TPR was close to its BET surface area when the crosssectional area of the active adsorptive atom was assumed to be $1.4 \times 10^{19} \mathrm{Cu}$-atoms $\mathrm{m}^{-2}$. As described by Grift et al. (1991), the determination of the surface area of attached copper particles $\left(\mathrm{S}_{\mathrm{Cu}}, \mathrm{m}^{2}-\mathrm{Cu}\right.$ g-resin $\left.{ }^{-1}\right)$ is based on the measurement 


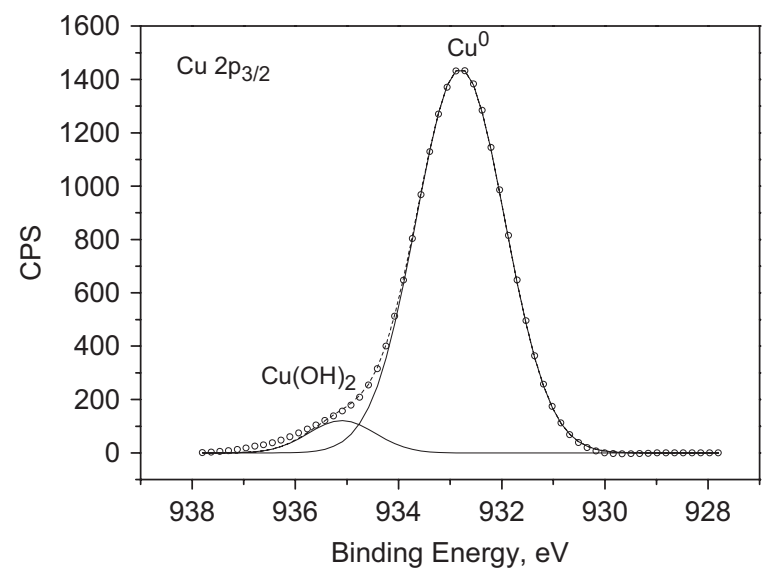

\begin{tabular}{cccc}
\hline \hline Peak & Centre & FWHM & Area \\
& $(\mathrm{ev})$ & $(\mathrm{ev})$ & $(\%)$ \\
$\mathrm{Cu}^{0}$ & 932.8 & 1.75 & 94 \\
$\mathrm{Cu}(\mathrm{OH})_{2}$ & 935.1 & 1.3 & 6 \\
\hline \hline
\end{tabular}

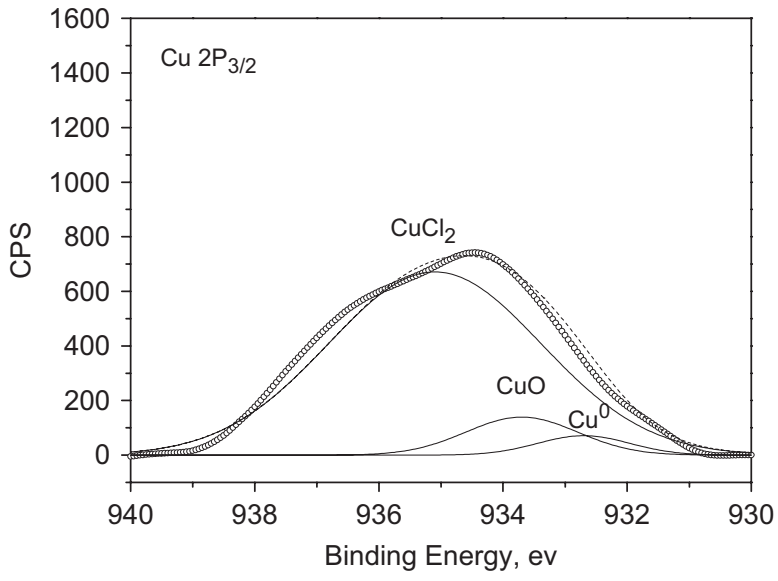

\begin{tabular}{ccc}
\hline \hline Peak & Centre & FWHM
\end{tabular}

(ev) (ev)

(\%)

$\mathrm{Cu}^{\circ}$

932.8

1.48

4

$\mathrm{Cu}$

$933.7 \quad 1.80$

10

$\mathrm{CuCl}_{2}$

935.1

3.44

86

Fig. 1 - XPS spectra of Cu2p $\mathrm{p}_{3 / 2}$ for (a) before; (b) after the dechlorination reaction for $10 \mathrm{~h}$.
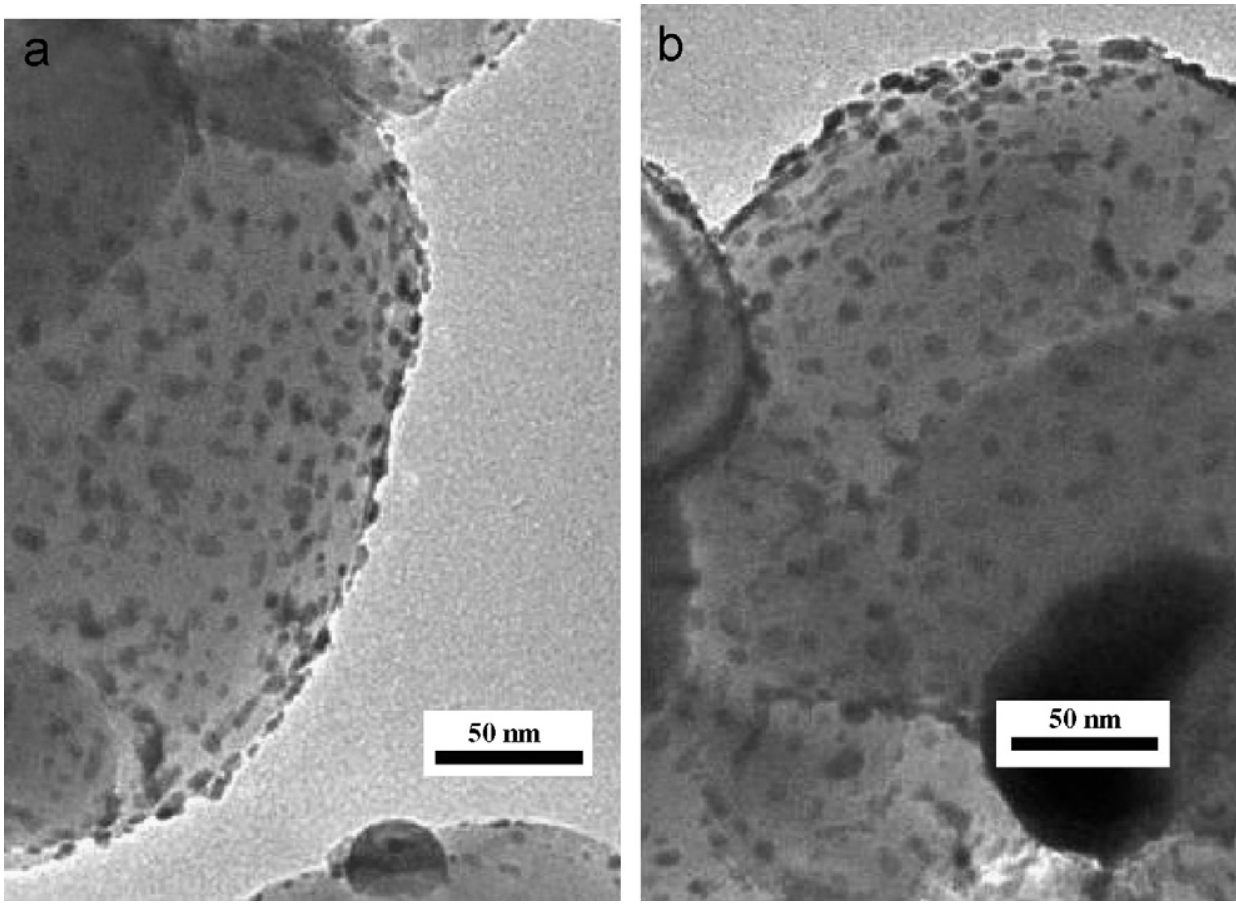

Fig. 2 - The TEM images of resin $\left(10 \mathrm{mg}-\mathrm{Cu}\right.$ g-resin $\left.^{-1}\right)$ for (a) before; (b) after the dechlorination reaction for $10 \mathrm{~h}$. The metallic particles appear as spots with high contrast. 
of hydrogen consumption after surface oxidation of the copper by $\mathrm{N}_{2} \mathrm{O}$.

Step 1:

$2 \mathrm{Cu}+\mathrm{N}_{2} \mathrm{O} \rightarrow \mathrm{Cu}_{2} \mathrm{O}+\mathrm{N}_{2}$ (copper surface atoms only).

Step 2:

$\mathrm{Cu}_{2} \mathrm{O}+\mathrm{H}_{2} \rightarrow 2 \mathrm{Cu}+\mathrm{H}_{2} \mathrm{O}$.

Compared to the area of the TCD signals of $1 \mathrm{~mL} \mathrm{H}_{2}$ $\left(40.9 \mu \mathrm{mol}\right.$ at $\left.1 \mathrm{~atm}, 25^{\circ} \mathrm{C}\right)$ passing through the reactor of TPR, the $\mathrm{H}_{2}$ consumption of various copper ions loading samples in the first and second TPR would be obtained; the numbers of total and surface copper atoms were calculated by multiplying a factor that expresses the stoichiometry of Eqs. (2) and (3). Copper surface area $\left(\mathrm{S}_{\mathrm{Cu}}\right)$ on the resin would be readily calculated with above related values.

$N_{\text {surf } \mathrm{Cu}}=\left(A_{\text {surf } \mathrm{Cu}} / \mathrm{A}_{1 \mathrm{~mL} \mathrm{H}}\right) 40.9 \times 10^{-6} \mathrm{~N}_{\mathrm{s}}$ (mole).

$\mathrm{S}_{\mathrm{Cu}}=\left(\mathrm{N}_{\text {surf,Cu }} \times \mathrm{N}_{\mathrm{av}}\right) /\left(1.4 \times 10^{19} \mathrm{~W}_{\text {resin }}\right)\left(\mathrm{m}^{2}-\mathrm{Cu} g-\mathrm{sample}^{-1}\right)$,

where $N_{\text {surf } \mathrm{Cu}}$ is the number of surface copper atoms; $A_{\text {surf } \mathrm{Cu}}$ is the area of the TCD signal for the second TPR; $A_{1 \mathrm{~mL} \mathrm{H}_{2}}$ is the area of the TCD signal for $1 \mathrm{~mL} \mathrm{H}_{2} ; \mathrm{N}_{\mathrm{s}}(=2)$ is the stoichiometry of Eq. (5); $N_{\text {av }}$ is Avogadro constant $\left(6.023 \times 10^{23} \mathrm{~mole}^{-1}\right)$; $\mathrm{W}_{\text {resin }}$ is the mass $(\mathrm{g})$ of the resin in the reactor of TPR.

The dispersion (D) of copper was defined as the ratio of the number of copper surface atoms and total number of copper atoms (Eq. (8)). In other words, $D$ is the fraction of the total of copper accessible to the reactant molecules. As Grift et al. (1991) described, the measurement of dispersion of $\mathrm{Cu}$ on the resin was based on the amount of the $\mathrm{H}_{2}$ consumption of the first and second TPR, named $Y$ and $X$, respectively. The reactions corresponding to the first and second TPR, respectively, are Eqs. (6) and (7).

Polymer- $\left(\mathrm{SO}_{3}\right)_{2}+\mathrm{H}_{2} \rightarrow \mathrm{Cu}^{0}+$ Polymer- $\left(\mathrm{SO}_{3}\right)_{2}$, hydrogen consumption $=\mathrm{Y}$,

$\mathrm{Cu}_{2} \mathrm{O}+\mathrm{H}_{2} \rightarrow 2 \mathrm{Cu}^{0}+\mathrm{H}_{2} \mathrm{O}$, hydrogen consumption $=\mathrm{X}$.

The dispersion of $\mathrm{Cu}$ on resin was calculated by

$D=N_{\text {surf Cu}} / N_{\text {tot } \mathrm{Cu}}=2 X / Y, D \leqslant 1$,

where $N_{\text {tot,Cu }}$ is total number of copper atoms. Assuming the copper particles in spherical shape, Boundart and DjegaMariadassou (1984) proposed an approximate conversion between dispersion $D$ and average particle size $d_{\mathrm{AV}}(\mathrm{nm})$.

$d_{\mathrm{AV}}=0.9 /$ dispersion $(\mathrm{nm})$.

Figs. 3(a) and (b) show the profiles of the first and second TPR, respectively. The values of $X_{i}$ and $Y_{i}(i=5,10,20,30,50)$ of these samples were normalized to the area of the TPR signal for $1 \mathrm{~mL} \mathrm{H}_{2}$. To establish the same base of the TPR profiles for various $\mathrm{Cu}$ loadings, samples of different weights were added to the reactor of TPR, $0.4 \mathrm{~g}$ for the $5 \mathrm{mg}-\mathrm{Cu}$ g-resin ${ }^{-1}, 0.3 \mathrm{~g}$ for the $10 \mathrm{mg}$-Cu g-resin ${ }^{-1}$, and $0.2 \mathrm{~g}$ for the 20 , 30 and $50 \mathrm{mg}-\mathrm{Cu}$ g-resin ${ }^{-1}$. Significant signals for initially consumed $\mathrm{H}_{2}$ were appeared at $250-290^{\circ} \mathrm{C}$ in the first TPR, but at $150-180^{\circ} \mathrm{C}$ in the second TPR. The difference of activated energy between sorbed $\mathrm{Cu}$ ions on the resin and $\mathrm{Cu}_{2} \mathrm{O}$ reduced by $\mathrm{H}_{2}$ may account for this observation. Table 1 lists the resulting values of $S_{\mathrm{Cu}}, \mathrm{D}$ and $d_{\mathrm{AV}}$ of $\mathrm{Cu}$ on the resin. $\mathrm{As} \mathrm{Cu}$ loading on the resin increases, the $S_{\mathrm{Cu}}$ increased from 0.50 to $0.68 \mathrm{Cu}-\mathrm{m}^{2}$ g-resin ${ }^{-1}$ for $\mathrm{Cu}$ loading between $5 \mathrm{mg}-\mathrm{Cu}$ g-resin ${ }^{-1}$ and $10 \mathrm{mg}$-Cu g-resin ${ }^{-1}$. However, it holds at the amount of approximate $0.55{\mathrm{Cu}-\mathrm{m}^{2} \text { g-resin }}^{-1}$ for $20 \mathrm{mg}-\mathrm{Cu}$ g-resin ${ }^{-1}$ up to $50 \mathrm{mg}$-Cu g-resin ${ }^{-1}$. Consequently, increasing the $\mathrm{Cu}$ loading on resin served initially to increase the number density rather than the size of particles on the resin. Then, a further increase led to agglomeration of $\mathrm{Cu}$ particles at the temperature of reduction, simultaneously indicated by an increase in the average particle size. The prepared resinsupported copper were characterized by ESCA, TEM, and TPR, indicating the values of exposed surface area of $\mathrm{Cu}^{0}$ on the resin without significant change during the period of reaction.

\subsection{Dechlorination of $\mathrm{CCl}_{4}$}

A conceptual model of the nanoscale zero valent copperresin- $\mathrm{CCl}_{4}$-water system incorporating concurrent the degradation reaction by $\mathrm{Cu}^{0}$ and sorption/desorption by the resin is similar to that proposed by Burris et al. (1998). The disappearance of $\mathrm{CCl}_{4}$ from aqueous solutions may be due to degradation reactions by zero valent copper or sorption onto the resin.

$-\mathrm{d} C_{\mathrm{w}} / \mathrm{dt}=k_{\mathrm{a}} C_{\mathrm{w}}+\alpha_{\mathrm{s}} C_{\mathrm{w}}-\alpha_{\mathrm{d}} C_{\mathrm{s}}$,

where $C_{w}$ and $C_{s}$ are the aqueous, and sorbed-phase $\mathrm{CCl}_{4}$ concentrations $\mu$ g per vial; $\alpha_{\mathrm{s}}$ and $\alpha_{\mathrm{d}}$ are the soprtion and desorption rate constants, respectively. The loss of total mass of $\mathrm{CCl}_{4}\left(C_{\mathrm{T}}\right)$ in a closed reactor was attributed to the degradation reaction by $\mathrm{Cu}^{0}$ and fitted with a first-order rate equation of the form

$-\mathrm{d} C_{\mathrm{T}} / \mathrm{dt}=k_{\mathrm{obs}} C_{\mathrm{w}}=k_{\mathrm{SA}} a_{\mathrm{s}} \rho_{\mathrm{m}} \mathrm{C}_{\mathrm{w}}$.

Eqs. (10) and (11) state the decline in the concentration of target contaminants in the batch system was caused only by reduction reaction at the $\mathrm{Cu}^{0}$ surface; however, the apparent concentration in the aqueous phase was reduced by the combination of sorption and reduction reaction. Regardless of the mechanism of sorption, Eq. (10) or (11) can be simplified as Eq. (1). Fig. 4(a) is the result of controlled experiment with 91-103\% recovery of total $\mathrm{CCl}_{4}$ mass. Fig. 4(b)-(f) separately present experimental results (the residual aqueous and total $\mathrm{CCl}_{4}$ mass in the vial) for the reaction of $0.2 \mathrm{~g}$ of $5,10,20,30$, $50 \mathrm{mg}$-Cu g-resin ${ }^{-1}$ with $1.05 \mathrm{mg} \mathrm{vial}^{-1}$ initial mass of $\mathrm{CCl}_{4}$. Additionally, Fig. 4(g) presents the residual aqueous $\mathrm{CCl}_{4}$ mass in the vial containing $0.3 \mathrm{~g}$ powdered copper over the period of reaction. As presented in Fig. 4(b)-(f), both total and aqueous $\mathrm{CCl}_{4}$ mass declined substantially. The rate of loss of total $\mathrm{CCl}_{4}$ mass obtained using $5 \mathrm{mg}$-Cug-resin ${ }^{-1}$ resembled that of $10 \mathrm{mg}^{-C u}$ g-resin ${ }^{-1}$, and both losses were significantly faster than those obtained using 20, 30, and $50 \mathrm{mg}$-Cu g-resin $^{-1}$. The first-order observed rate constants $\left(k_{\text {obs }}\right)$ of the dechlorination of $\mathrm{CCl}_{4}$ in contact with $\mathrm{Cu}$ g-resin ${ }^{-1}$ were obtained from the slope of a plot of total $\mathrm{CCl}_{4}$ loss rate $(-\mathrm{dC} / \mathrm{dt})$ versus $\mathrm{CCl}_{4}$ concentration in the aqueous phase, $C_{\mathrm{w}}$ in $\mathrm{mg}-\mathrm{CCl}_{4} \mathrm{vial}^{-1}$, using linear least-squares analysis. The $k_{\mathrm{obs}}$ values were $1.644 \pm 0.174, \quad 2.046 \pm 0.132, \quad 0.342 \pm 0.042, \quad 0.209 \pm 0.011$ and $0.264 \pm 0.03 \mathrm{~h}^{-1}$ for $5,10,20,30$, and $50 \mathrm{mg}$-Cu g-resin ${ }^{-1}$, respectively (shown in Table 1 ). The values of $k_{\mathrm{SA}}$ were 
a

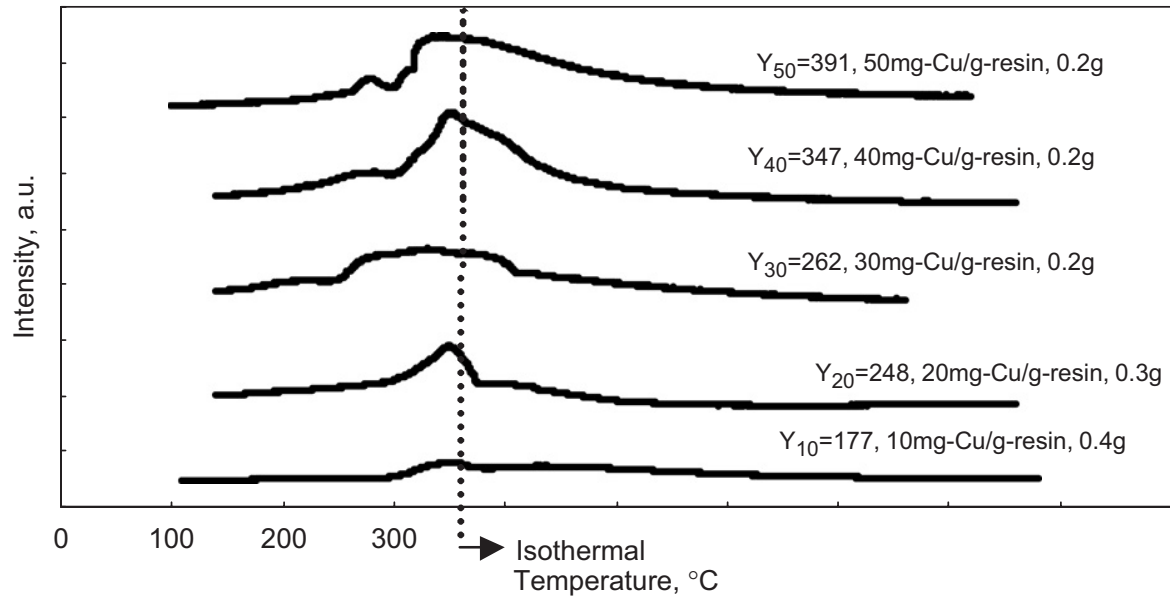

b

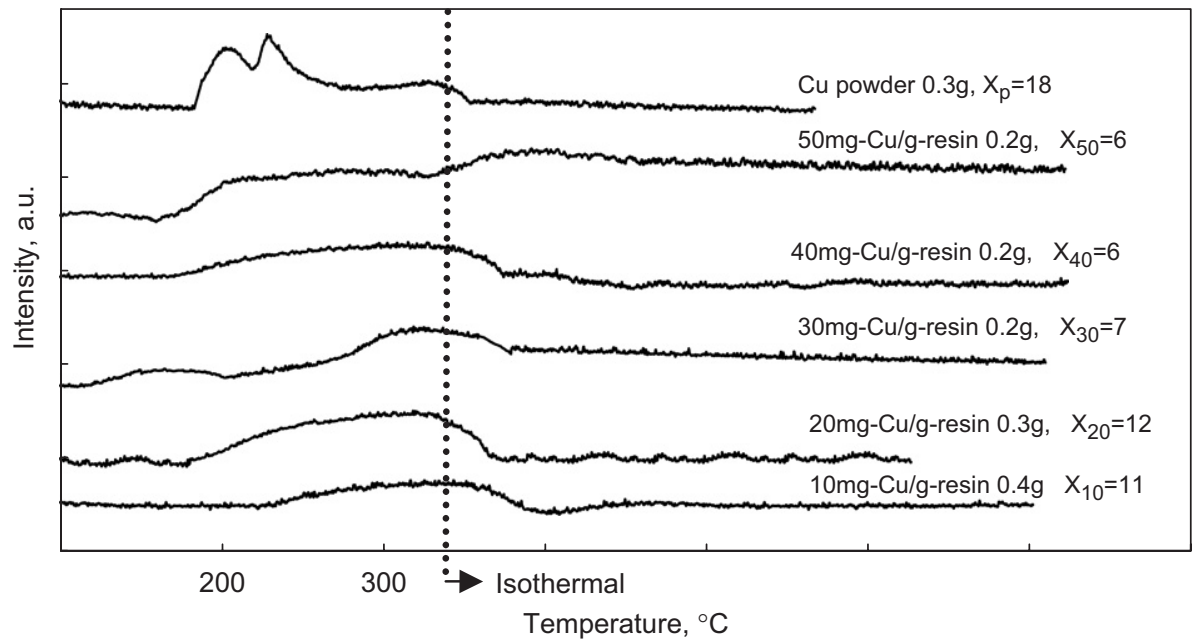

Fig. 3 - Consumption of $\mathrm{H}_{2}$ during temperature programmed reduction of nano-Cu/resin: (a) after complete oxidation (the first TPR); (b) after surface oxidation (the second TPR).

Table 1 - The specific surface area, dispersion and average diameter of particles, and its reactivity to $\mathrm{CCl}_{4}$

\begin{tabular}{|c|c|c|c|c|c|c|c|c|}
\hline $\begin{array}{l}\text { Sample (mg-Cu } \\
\text { g-resin } \\
\text {-1) }\end{array}$ & $\begin{array}{l}\mathrm{W}_{\text {sample }} \\
\text { (g) }\end{array}$ & $\begin{array}{c}\mathrm{H}_{2} \text { consumption } \\
\left(\text { mole g-resin }^{-1}\right)\end{array}$ & $\begin{array}{c}\mathrm{S}_{\mathrm{Cu}}{ }^{\mathrm{a}}\left(\mathrm{m}^{2}-\mathrm{Cu}\right. \\
\text { g-resin } \\
-1\end{array}$ & $\begin{array}{l}\text { Dispersion } \\
\text { (D) }\end{array}$ & $\begin{array}{l}d_{\mathrm{AV}} \\
(\mathrm{nm})\end{array}$ & $k_{\mathrm{obv}}^{\mathrm{b}}\left(\mathrm{h}^{-1}\right)$ & $\begin{array}{l}k_{\mathrm{SA}} \times 10^{-2 \mathrm{~b}} \\
\left(\mathrm{~L} \mathrm{~m}^{-2} \mathrm{~h}^{-1}\right)\end{array}$ & $\frac{k_{\mathrm{n}, \mathrm{SA}}}{k_{\mathrm{p}, \mathrm{SA}}}$ \\
\hline 5 & 0.4 & 11.51 & 0.50 & 0.127 & 7 & $1.644 \pm 0.174$ & $24.90 \pm 2.64$ & 125 \\
\hline 10 & 0.3 & 15.86 & 0.68 & 0.089 & 10 & $2.046 \pm 0.132$ & $22.49 \pm 1.45$ & 112 \\
\hline 20 & 0.2 & 13.04 & 0.56 & 0.051 & 18 & $0.342 \pm 0.042$ & $4.57 \pm 0.57$ & 23 \\
\hline 30 & 0.2 & 12.02 & 0.52 & 0.034 & 26 & $0.209 \pm 0.011$ & $3.03 \pm 0.16$ & 15 \\
\hline 50 & 0.2 & 12.28 & 0.53 & 0.031 & 29 & $0.264 \pm 0.03$ & $3.75 \pm 0.42$ & 14 \\
\hline Powdered $\mathrm{Cu}$ & 0.3 & 23.87 & 1.03 & - & - & $0.028 \pm 0.002$ & $0.20 \pm 0.02$ & 1 \\
\hline
\end{tabular}

obtained by normalizing $k_{\mathrm{obs}}$ according to the $\mathrm{S}_{\mathrm{Cu}}$ and the mass concentration of the sample $\left(0.2 \mathrm{~g} \mathrm{Cu}^{\%} / \mathrm{resin}\right.$ per $15 \mathrm{~mL}$ amber serum vial). As indicated in Table 1 , the $k_{\mathrm{SA}}$ of nanoscale $\mathrm{Cu}$ particles (named $k_{\mathrm{n}, \mathrm{SA}}$ ) was 110-120 times higher than that (named $k_{\mathrm{p}, \mathrm{SA}}$ ) of commercial powdered $\mathrm{Cu}$ particles when the $\mathrm{Cu}^{0}$ particle size was about $10 \mathrm{~nm}$. However, for diameters of $20-30 \mathrm{~nm}$, the ratio of $k_{\mathrm{n}, \mathrm{SA}} / k_{\mathrm{p}, \mathrm{SA}}$ was around 10-20. This indicates the size dependence of the reactivity of small copper nanoparticles varies discontinuously. 
a

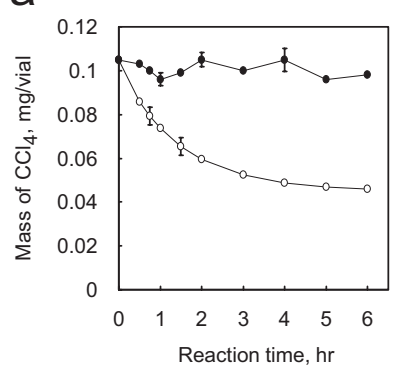

e

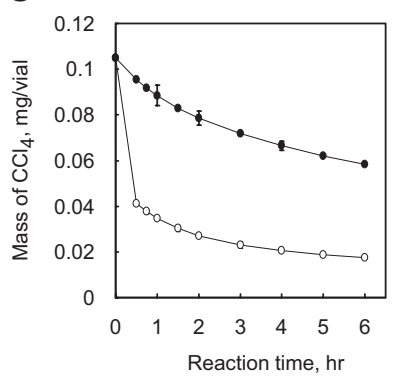

b

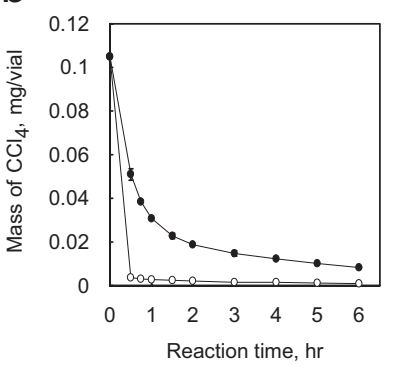

f

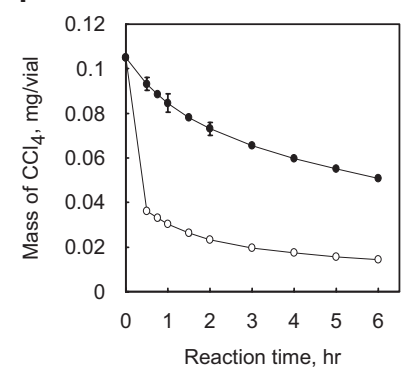

C

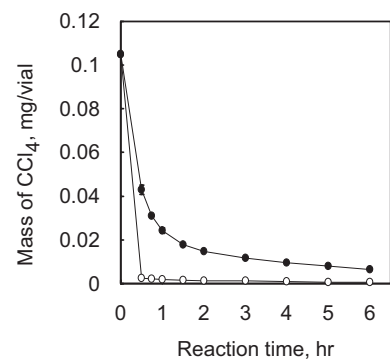

d

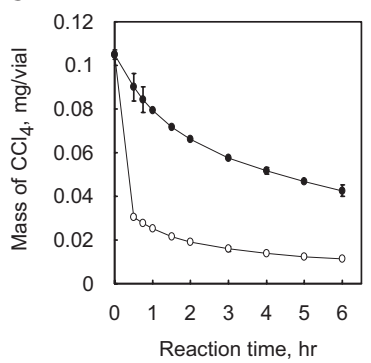

g

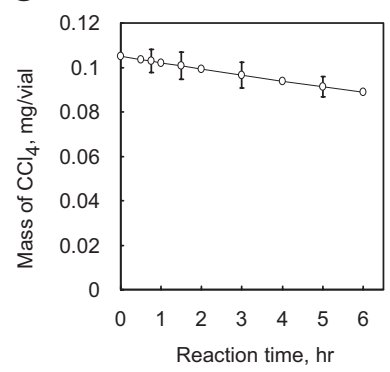

Fig. 4 - The residual aqueous and total $\mathrm{CCl}_{4}$ mass with $95 \%$ confidence interval for (a) control with resin only, (b) $5 \mathrm{mg}$-Cu g-resin ${ }^{-1}$; (c) $10 \mathrm{mg}$-Cu g-resin ${ }^{-1}$; (d) $20 \mathrm{mg}$-Cu g-resin $^{-1}$; (e) $30 \mathrm{mg}$-Cu g-resin ${ }^{-1}$; (f) $50 \mathrm{mg}$-Cu g-resin $^{-1}$; (g) Cu powder. ( $O$ ) referred to the residual aqueous $\mathrm{CCl}_{4}$ mass; (O) referred to the residual total $\mathrm{CCl}_{4} \mathrm{mass}_{\text {. }}$

\section{Conclusions}

In this work, the size dependence of reactivity toward carbon tetrachloride was studied via synthesizing copper nanoparticles with uniform size dispersed on a cation resin. The $k_{\mathrm{n}, \mathrm{SA}}$ was sharply increased by a factor of 110-120 when $\mathrm{Cu}^{0}$ particle size was close to $10 \mathrm{~nm}$. However, for diameters of $20-30 \mathrm{~nm}$, the ratio of $k_{\mathrm{n}, \mathrm{SA}} / k_{\mathrm{p}, \mathrm{SA}}$ was around $10-20$, indicating the reactivity of small $\mathrm{Cu}$ particles $(\sim 10 \mathrm{~nm})$ varies discontinuously. Thus, most variability in previous $k_{\mathrm{SA}}$ is attributed to the presence of small nanoparticles.

\section{Acknowledgement}

The authors would like to thank the National Science Council of the Republic of China for financially supporting this research under Contract No. NSC 92-2211-E-002-006.

\section{R E F E R E N C E S}

Agrawal, A., Tratnyek, P.G., 1996. Reduction of nitro aromatic compounds by zero-valent iron metal. Environ. Sci. Technol. 30, 153-160.

Bond, G.C., Namijo, S.N., 1989. An improved procedure for estimating the metal surface area of supported copper catalysts. J. Catal. 118, 507-510.

Boundart, M., Djega-Mariadassou, G., 1984. Kinetics of Heterogeneous Catalytic Reactions. Princeton University Press, Princeton, NJ, pp. 20-26.

Burris, D.R., Allen-King, R.M., Manoranjan, V.S., Campbell, T.J., Loraine, G.A., Deng, B., 1998. Chlorination ethene reduction by cast iron: sorption and mass transfer. J. Environ. Eng. 10, 1012-1019.

Cantrell, K.J., Kaplan, D.I., Gilmore, T.J., 1997. Injection of colloidal $\mathrm{Fe}^{0}$ particles in sand with shear-thinning fluids. J. Environ. Eng., ASCE, 786-791.

Cao, J., Elliott, D., Zhang, W.X., 2005. Perchlorate reduction by nanoscale iron particles. J. Nanopart. Res. 7, 499-506.

Choe, S., Lee, S.H., Chang, Y.Y., Hwang, K.Y., Khim, J., 2001. Rapid reductive destruction of hazardous organic compounds by nanoscale $\mathrm{Fe}^{0}$. Chemosphere 42, 367-372.

Evans, J.W., Wainwright, M.S., Bridgewater, A.J., Young, D., 1983. On the determination of copper surface area by reaction with nitrous oxide. J. Appl. Catal. 7, 75-83.

Feng, J., Lim, T.T., 2005. Pathways and kinetics of carbon tetrachloride and chloroform reductions by nano-scale $\mathrm{Fe}$ and Fe/Ni particles: comparison with commercial micro-scale Fe and Zn. Chemosphere 59, 1267-1277.

Gillham, R.W., O'Hannesin, S.F., 1994. Enhanced degradation of halogenated aliphatics by zero-valent iron. Ground Water 32, 958-967.

Grift, C.J.G., Wielers, A.F.H., Joghi, B.P.J., Beijnum, J., Boer, M., Versluus-Helder, M., Gues, J.W., 1991. Effect of the reduction treatment on the structure and reactivity of silica-supported copper particles. J. Catal. 131, 178-189.

He, F., Zhao, D., 2005. Preparation and characterization of a new class of starch-stabilized bimetallic nanoparticles for degradation of chlorinated hydrocarbons in water. Environ. Sci. Technol. 39, 3314-3320.

Henry, C.R., 2000. Catalytic activity of supported nanometer-sized metal clusters. Appl. Surf. Sci. 164, 252-259.

Kanel, S.R., Manning, B., Charlet, L., Choi, H., 2005. Removal of arsenic(III) from groundwater by nanoscale zero-valent iron. Environ. Sci. Technol. 39, 1291-1298.

Li, F., Vipulanandan, C., Mohanty, K.K., 2003. Microemulsion and solution approaches to nanoparticles iron production for degradation of trichloroethylene. J. Colloids Surf. A: Physicochem. Eng. Aspects 223, 103-112. 
Liao, C.H., Kang, S.F., Hsu, Y.W., 2003. Characteristics of reductive removal of nitrate by suspended zero-valent iron powder. J. Chinese Inst. Environ. Eng. 13, 251-261.

Lien, H.L., Zhang, W.X.J., 1999. Transformation of chlorinated methanes by nanoscale iron particles. Environ. Eng., ASCE 9, 1042-1047.

Lin, C.J., Lo, S.L., Liou, Y.H., 2005. Degradation of aqueous carbon tetrachloride by nanoscale zerovalent copper on a cation resin. Chemosphere 59, 1299-1307.

Liou, Y.H., Lo, S.L., Kuan, W.H., Lin, C.J., Weng, S.C., 2006. Effect of precursor concentration on the characteristics of nanoscale zerovalent iron and its reactivity of nitrate. Water Res. 40, 2485-2492.

Liu, Y., Majetich, S.A., Tilton, R.D., Sholl, D.S., Lowry, G.V., 2005. TCE dechlorination rates, pathways, and efficiency of nanoscale iron particles with different properties. Environ. Sci. Technol. 39, 1338-1345.

Lowry, G.V., Johnson, K.M., 2004. Congener-specific dechlorination of dissolved PCBs by microscale and nanoscale zerovalent iron in a water/methanol solution. Environ. Sci. Technol. 38, 5208-5216.

Matheson, L.J., Tratnyek, P.G., 1994. Reductive dehalogenation of chlorinated methanes by iron metal. Environ. Sci. Technol. 28, 2045-2053.
Meyer, D.E., Wood, K., Bachas, L.G., Bhattacharyya, D., 2004. Degradation of chlorinated organics by membrane-immobilized nanosized metals. Environ. Progr. 23, 232-242.

Orth, W.S., Gillham, R.W., 1996. Dechlorination of trichloroethene in aqueous solution using $\mathrm{Fe}^{\mathrm{O}}$. Environ. Sci. Technol. 30, 66-71.

Ponder, S.M., Darab, J.G., Mallouk, T.E., 2000. Remediation of Cr(VI) and $\mathrm{Pb}(\mathrm{II})$ aqueous solutions using supported nanoscale zerovalent iron. Environ. Sci. Technol. 34, 2564-2569.

Schrick, B., Blough, J.L., Jones, A.D., Mallouk, T.E., 2002. Hydrodechlorination of trichloroethylene to hydrocarbons using bimetallic nickel-iron nanoparticles. Chem. Mater. 14, 5140-5147.

Siantar, D.P., Scheier, C.G., Chou, C.S., Reinhard, M., 1996. Treatment of 1, 2-Dibromo-3-chloropropane and nitrate-contaminated water with zero-valent iron or hydrogen/palladium catalysts. Water Res. 30, 2315-2322.

Su, C., Puls, R.W., 1999. Kinetics of trichloroethene reduction by zero-valent iron and tin: pretreatment effect apparent activation energy and intermediate products. Environ. Sci. Technol. 33, 163-168.

Wang, C.B., Zhang, W.X., 1997. Synthesizing nanoscale iron partical for rapid and complete dechlorination of TCE and PCBs. Environ. Sci. Technol. 31, 2154-2156. 